\title{
A Microbial Fermentation Mixture Reduces Fusarium Head Blight and Promotes Grain Weight but does not impact Septoria tritici blotch
}

\author{
Tony Twamley $\cdot$ Mark Gaffney $\cdot$ Angela Feechan $\mathbb{B}$
}

Accepted: 30 September 2021 / Published online: 19 October 2021

(C) The Author(s) 2021, corrected publication 2022

\begin{abstract}
Fusarium graminearum and Zymoseptoria tritici cause economically important diseases of wheat. $F$. graminearum is one of the primary causal agents of Fusarium head blight (FHB) and Z. tritici is the causal agent of Septoria tritici blotch (STB). Alternative control methods are required in the face of fungicide resistance and EU legislation which seek to cut pesticide use by 2030 . Both fungal pathogens have been described as either hemibiotrophs or necrotrophs. A microbial fermentation-based product (MFP) was previously demonstrated to control the biotrophic pathogen powdery mildew, on wheat. Here we investigated if MFP would be effective against the non-biotrophic fungal pathogens of wheat, $F$. graminearum and $Z$. tritici. We assessed the impact of MFP on fungal growth, disease control and also evaluated the individual constituent parts of MFP.
\end{abstract}

Supplementary Information The online version contains supplementary material available at https://doi. org/10.1007/s10658-021-02396-4.

T. Twamley · A. Feechan $(\bowtie)$

School of Agriculture and Food Science, University

College Dublin, Dublin, Ireland

e-mail: angela.feechan@ucd.ie

T. Twamley

e-mail: anthony.twamley@ucd.ie

M. Gaffney

Alltech Crop Science, Alltech European Bioscience

Centre, Dunboyne, Ireland

e-mail: mgaffney@alltech.com
Antifungal activity towards both pathogens was found in vitro but MFP only significantly decreased disease symptoms of FHB in planta. In addition, MFP was found to improve the grain number and weight, of uninfected and $F$. graminearum infected wheat heads.

Keywords Wheat Fusarium graminearum .

Zymoseptoria tritici $\cdot$ Microbial fermentation mixture

\section{Introduction}

Necrotrophic pathogens activate cell death in the host and extract nutrients from the resulting dead tissue. Whereas biotrophic pathogens derive nutrients from the living tissue of its plant host. Other pathogens fall between these two groups, Fusarium graminearum and Zymoseptoria tritici for example, both have biotrophic and necrotrophic stages of infection. The former has been described as a hemibiotroph (Thapa et al., 2018) or necrotroph (Makandar et al., 2012) and the latter as either a hemibiotroph (Kettles \& Kanyuka, 2016) or a latent necrotroph (Meile et al., 2018). Controlling these pathogens is a challenge to wheat production particularly with EU targets to decrease fungicide use under Directive 2009/128, the Sustainable Use Directive.

$F$. graminearum is one of the primary causal agents of Fusarium head blight (FHB). Epidemics occur in the USA, China, the EU, UK, Africa, Brazil and elsewhere every four or five years and between $10-70 \%$ yield losses have occurred in epidemic years (Figueroa et al., 
2017; Yi et al., 2018). Breeding for host resistance is recognised to be the most efficient way of controlling FHB. However, developing resistant wheat varieties is challenging as effective resistance genes can also be linked to unsuitable agronomical traits such as grain quality unsuitable for baking (Kocourková et al., 2008; Shin et al., 2014; Yi et al., 2018).

The most common control method for FHB is fungicide treatment (Malbrán et al., 2020) and applications at anthesis can be effective (Rojas et al., 2020). Alternatives to classical fungicides have been shown to reduce FHB symptoms in wheat including applications of botanicals such as tannic acid, antifungal solutions made from Chinese galls (Galla chinensis), and buckthorn bark (Frangula alnus) (Forrer et al., 2014). Microbial alternatives to control FHB include antifungal strains of bacteria (Franco et al., 2011; Jochum et al., 2006; Khan \& Doohan 2009; Palazzini et al., 2018) and yeast (Khan et al., 2001; Schisler et al., 2002). Strains of the yeast genus Cryptococcus were found to reduce FHB disease severity in the field (Schisler et al., 2002). Similarly, the fungus Clonostachys rosea also controls FHB under field conditions (Xue et al., 2009). The application of chitosan has direct antifungal activity and can act as an elicitor, activating plant defences (Kheiri et al., 2016). An extracellular protease produced via fermentation of the strawberry pathogen Acremonium strictum, has been used as a biostimulant effectively in wheat, again increasing resistance to FHB (Chalfoun, et al., 2018a).

Septoria tritici blotch (STB) caused by Z. tritici is the most prevalent disease of wheat in temperate climates including the EU where it is estimated to cost growers €280-1,200 million annually as a result of yield losses and control costs (Figueroa et al., 2017). Control of STB is also typically via growing resistant varieties and the use of chemical fungicides (Kristoffersen et al., 2020). However, the pathogen has shown resistance to fungicides including azoles (McDonald et al., 2019). Alternatives to classical fungicides have also been explored for example, elicitors of plant defences such as $\lambda$-carrageenan, CpG-ODN, glycine betaine, Spirulina platensis, and ergosterol (Le Mire et al., 2019). Surfactin extracted from the strain Bacillus amyloliquefaciens S499 protects against Z. tritici and activates plant defence (Le Mire et al., 2018). Antifungal Lactobacillus strains were capable of inhibiting STB disease development and significantly reduced the diseased leaf area covered with pycnidia (Lynch et al., 2016). The polysccharide tramesan, secreted by the fungus Trametes versicolor was shown to significantly decrease STB disease incidence in controlled conditions as well as in the field (Scala et al., 2020). Previous studies also reported synergism between elicitors and fungicide combinations. Such synergistic combinations of elicitors and fungicides show potential to reduce fungicide inputs. This was found with the combination of the agricultural biostimulant PSP1 (based on a fungal protease elicitor from Acremonium strictum) together with a fatty acid methyl esters-based adjuvant and a fungicide containing trifloxystrobin and cyproconazole. Resistance against soybean target spot (STS) caused by the fungus Corynespora cassiicola was greater after the combination treatment compared to PSP1 or the fungicide individually suggesting the adjuvant caused a synergistic effect between both treatments (Chalfoun et al., 2018b).

Previously we demonstrated that a microbial fermentation-based product (MFP) could control powdery mildew on wheat reducing disease symptoms and the product components were found to act synergistically (Twamley et al., 2019). The aim of this study was to assess the efficacy of MFP and its components, to control fungal growth and disease caused by the non-biotrophic fungal pathogens $F$. graminearum and Z. tritici. In addition, the impact of MFP on grain number and weight following $F$. graminearum infection was assessed.

\section{Materials and Methods}

\section{Plant material}

Seeds of the wheat (Triticum aestivum) cultivar (cv) Avatar, which is moderately resistant to FHB (resistance rating 6) and susceptible to STB (resistance rating 4) (DAFM, 2019), were removed from storage at $4^{\circ} \mathrm{C}$, sterilised in $20 \%$ bleach for four minutes and rinsed in sterilised distilled water at least four times. To induce germination, seeds were incubated on moist filter paper in sealed petri dishes (15-20 seeds / dish) under sterile conditions in darkness at $24^{\circ} \mathrm{C}$ for four days and then transferred to and grown in pots of John Innes No.2 compost (Westland Horticulture, United Kingdom). Seedlings used for Z. tritici disease assays received no other nutritional amendments and were grown under a 15:9 light dark photoperiod at 
$200 \mu \mathrm{mol} \mathrm{m} \mathrm{m}^{-2} \mathrm{~s}^{-1}$ at a constant temperature of $22^{\circ} \mathrm{C}$, $80 \%$ humidity in a growth chamber and kept under these conditions for the full duration of the experiments. Seedlings grown for FHB assays were vernalised (Cahalan \& Law, 1979) under a 12:12 light dark photoperiod at $45 \mu \mathrm{mol} \mathrm{m} \mathrm{m}^{-2} \mathrm{~s}^{-1}$ at a constant temperature of $6{ }^{\circ} \mathrm{C}$ for 3 months and then potted on, into 2 L pots of John Innes No.3 compost (Westland Horticulture, United Kingdom) with three plants per pot. These plants were then grown under a 16:8 light dark photoperiod at $200 \mu \mathrm{mol} \mathrm{m} \mathrm{m}^{-2} \mathrm{~s}^{-1}$ at a constant temperature of $20{ }^{\circ} \mathrm{C}$ and $80 \%$ humidity and kept under these conditions for the full duration of the experiments in a growth chamber. For phytotoxicity evaluation assays, germinated cv Avatar seeds were transferred to and grown in $7 \mathrm{~cm} \times 7 \mathrm{~cm}$ pots of John Innes No.2 compost, with no other nutritional amendments under either high light, $200 \mu \mathrm{mol} \mathrm{m} \mathrm{m}^{-2}$ (HL) or low light, $45 \mu \mathrm{mol} \mathrm{m} \mathrm{m}^{-2} \mathrm{~s}^{-1}$ (LL) under a 16-h day photoperiod at a constant temperature of $20{ }^{\circ} \mathrm{C}$ and $80 \%$ humidity.

\section{Elicitor treatments}

The test product was a liquid microbial fermentation mixture (MFP) consisting of a proprietary blend containing bacteria and yeast from fermentation brewing media and $4.7 \%$ elemental copper as copper sulphate $\left(\mathrm{CuSO}_{4}\right)($ Alltech Crop Science, KY, USA) (Twamley et al., 2019). The product was prepared as per manufacturer's recommendations of $0.5 \% \mathrm{~V} / \mathrm{V}$, and for some experiments, double the recommended rate at $1 \% \mathrm{~V} / \mathrm{V}$, in sterile distilled water. A solution of MFP without the copper component was supplied. This was also diluted $0.5 \% \mathrm{~V} / \mathrm{V}$ in sterile distilled water and is referred to as $\mathrm{nC}$ herein. Solutions of $\mathrm{CuSO}_{4}$ containing $4.7 \%$ elemental copper were made for experiments and diluted $0.5 \% \mathrm{~V} / \mathrm{V}$ in sterile distilled water. This copper solution is referred to herein as CS. Sterilised distilled water was used as the control treatment. The application timings were chosen based on the advice of the MFP suppliers (Alltech Crop Science, KY, USA). Wheat cv Avatar plants were treated twice, with applications one week apart, with either MFP, or the components $\mathrm{nC}, \mathrm{CS}$, or water as the control. To limit the effect on product performance that could be caused by batch to batch variation, a single batch of MFP and $\mathrm{nC}$ were used for all experiments.
In vitro sensitivity assays

In vitro assays were performed to evaluate the antifungal activity of MFP and its component parts, nC and CS, against $F$. graminearum isolate GZ3639 (Thapa et al., 2018) and Z. tritici isolate IPO323 (Kema \& van Silfhout, 1997). Potato dextrose agar (PDA) plates were amended with one of three dilutions $(0.5 \%, 0.34 \%$ and $0.17 \%)$ of one of three treatments; MFP, $\mathrm{nC}$ or CS. Control plates were amended with sterilised distilled water.

To test the MFP sensitivity of $F$. graminearum, plugs of the fungal mycelium were taken from the edge of 7-day-old fungal PDA cultures using a sterilised $8 \mathrm{~mm}$ diameter corkborer and were placed on the surface of the test PDA plates, three plugs per plate, equally spaced around the plate rim. Plates were sealed and incubated at $28^{\circ} \mathrm{C}$ in darkness. The radial growth of the mycelium was recorded every day for 7 days or until growth had reached the capacity of the plate. Three radial measurements were made from the circumference of each plug and the average of these was recorded. This assay comprised of three independent experiments each of which included three plates per treatment dilution and each plate had three plugs of $F$. graminearum fungal mycelia.

Prior to use, the $Z$. tritici isolate was cultured on PDA and grown at $20^{\circ} \mathrm{C}$ under white light supplemented with blue/black ultraviolet (UV-A) light under a 12:12 light day photoperiod for 7 days. Plugs of this growth were taken using a sterilised $8 \mathrm{~mm}$ diameter corkborer and placed on the surface of the test PDA plates, three plugs per plate, equally spaced around the plate. Plates were sealed and incubated for two weeks. Three radial measurements were made from each plug and the average of these was recorded. The assay comprised of three independent experiments each including three plates per treatment dilution and each plate containing three plugs of $Z$. tritici.

\section{FHB disease assay}

The first treatment was applied once head formation was visible (Zadok's growth stage 50) (Zadoks et al., 1974).

Once wheat head formation became visible, plants were treated with $0.5 \% \mathrm{MFP}, \mathrm{nC}, \mathrm{CS}$ or water and one week later treated again. An $8 \mathrm{ml}$ volume of treatment was spray applied to each plant using a hand-held 
spray bottle. Plugs of $F$. graminearum isolate GZ3639 (Thapa et al., 2018) were grown on potato dextrose agar (PDA) for 7 days and plugs of the fresh mycelial growth were transferred to flasks of mung bean broth and placed on a shaker plate rotating at $120 \mathrm{rpm}$ at 25 ${ }^{\circ} \mathrm{C}$ to allow macroconidia to develop for 7 days. The suspension was adjusted to $1 \times 10^{6}$ macroconidia per $\mathrm{ml}$ and Tween 20 was added such that the final suspension contained $0.02 \%$ Tween 20 . For mock-inoculations, sterilised distilled water containing $0.02 \%$ Tween 20 was used. At mid-anthesis, wheat heads were point inoculated by pipetting $10 \mu \mathrm{l}$ of a fresh $F$. graminearum macroconidia suspension or a mock suspension control, directly onto the anthers of the middle florets. Inoculated florets were marked with a dot using a black permanent marker. Two heads per plant were inoculated. Immediately after inoculation, inoculated heads were covered with plastic bags and sealed to maintain high humidity. After 2 days, bags were removed. At 7, 14, and 21 days post inoculation (dpi), the percentage of disease coverage was recorded. After ripening, plants were dried out, heads harvested, and number and weight of grains per head recorded. The assay comprised of three independent experiments each including 12 plants per treatment and two heads per plant $(n=72)$.

\section{Zymoseptoria tritici disease assay}

Three-week-old wheat seedlings were spray treated with either a $0.5 \%$ or a $1 \%$ rate of MFP and one week later treated again. Sterilised distilled water was used as a control. One day after the second treatment, plants were inoculated with Z. tritici (IPO323) (Kema \& van Silfhout, 1997). Z. tritici was grown on PDA for 7 days at $20{ }^{\circ} \mathrm{C}$ under white light supplemented with blue/black ultraviolet (UV-A) light under a 12:12 light dark photoperiod. Fungal spores from the PDA cultures were harvested and spore concentration was adjusted to $1 \times 10^{6}$ per $\mathrm{ml}$ in water containing $0.02 \%$ Tween 20. A $4 \mathrm{ml}$ volume of the spore suspension was spray applied to each wheat seedling (Shin et al., 2014) using a hand-held spray bottle. Control plants were sprayed with $4 \mathrm{ml}$ of $0.02 \%$ Tween 20 solution. To ensure high humidity, plants were covered with polythene bags immediately after inoculation. After 3 days, bags were removed. At 21 days post inoculation (dpi), percentage diseased area and pycnidia coverage were estimated using James' key and the Eyal-Brown scale respectively (Eyal et al., 1987). The assay comprised of two independent experiments each including three leaves per plant of ten plants per treatment $(n=60)$.

Phytotoxicity assay

To investigate the phytotoxic effect of MFP on wheat seedlings, two-week-old wheat cv Avatar seedlings (three plants per treatment per light intensity level) were treated with a $4 \mathrm{ml}$ volume of either water, $0.5 \%$ MFP, $0.5 \% \mathrm{nC}$, or $0.5 \% \mathrm{CS}$, and one week later, one leaf segment from each of three plants were taken and boiled in the vital stain, trypan blue solution $(0.4 \%)$ for 20 minutes, rinsed in water and de-stained in chloral hydrate solution $(2.5 \mathrm{~g} / \mathrm{ml})$ overnight (Koch \& Slusarenko, 1990). Leaf samples were mounted on slides with $80 \%$ glycerol for microscopic analysis of dead cells. Non-viable cells stain blue, viable cells remain unstained. Images of four representative leaf sections per leaf were taken and the proportion of symptoms were measured using ImageJ (Schneider et al., 2012). Two independent experiments were performed $(n=36)$. CS treatments were only included under $200 \mu \mathrm{mol} \mathrm{m} \mathrm{m}^{-2} \mathrm{~s}^{-1}$ conditions. For microscopy analysis, leaf samples were mounted onto slides with $80 \%$ glycerol and examined under a light microscope (Leica DM5500B).

\section{Statistical analysis}

All data were analysed using analysis of variance (ANOVA) and multiple comparison tests, which were performed using a generalized linear model and the Tukey test by the multcompView and emmeans functions of R statistical software (R Core Team, 2016).

Data from $F$. graminearum in vitro experiments and FHB grain analysis used a quasi-Poisson distribution. Data from STB disease spread used a Poisson distribution and data from $Z$. tritici in vitro experiments and FHB disease score used a negative-binomial distribution. Figures were produced on R statistical software (R Core Team, 2016) and Microsoft Excel.

The interaction between $\mathrm{CS}$ and $\mathrm{nC}$ was examined using Abbott's equation for synergy (Gisi, 1996). The expected efficacy $\left(\mathrm{E}_{\text {exp }}\right)$ was calculated using $\mathrm{E}_{\text {exp }}=\mathrm{a}$ $+\mathrm{b}-(\mathrm{ab} / 100)$, where $\mathrm{a}$ is the $\%$ reduction in radial 
growth caused by $\mathrm{nC}$ alone and $\mathrm{b}$ is the \% reduction in radial growth by CS alone. The synergistic effect was calculated by determining the ratio between the observed efficacy $\mathrm{E}_{\mathrm{obs}}$ and $\mathrm{E}_{\text {exp }}$. A ratio equal to 1 indicates additivity, ratios $>1$ indicate synergy, and ratios $<1$ indicate antagonism (Rahman et al., 2014).

\section{Results}

Fusarium graminearum in vitro sensitivity assays

To test the sensitivity of $F$. graminearum to MFP and to compare the effect of MFP's constituent parts, $\mathrm{nC}$ (MFP without copper component) and $\mathrm{CS}\left(\mathrm{CuSO}_{4}\right.$ containing $4.7 \%$ elemental copper), the fungus was grown on agar at three different concentrations of each $(0.17 \%, 0.34 \%$ and $0.5 \%)$ and growth recorded over seven days (Supplementary Fig. S1 and Supplementary Table S1). Fungal hyphal growth was pink on the control plates and $\mathrm{nC}$ but was yellow on CS and orange on MFP plates (Fig.1a). Radial growth of $F$. graminearum was compared between the treatments at 4 dpi (since at this timepoint fungal growth on the water control had filled the plates) (Fig. 1b). Fungal growth on the plates with $0.5 \%$ and $0.34 \%$ rates of MFP was significantly $(\mathrm{p}<0.001)$ lower than growth on control plates, $44.3 \%$ and $40.4 \%$ lower respectively. However, all three concentrations of CS $0.17 \%, 0.34 \%$ and $0.5 \%$ significantly $(\mathrm{p}<0.001)$ reduced fungal growth, by $19.6 \%, 59.3 \%$ and $90.8 \%$ respectively. At $4 \mathrm{dpi}$, growth on $0.34 \%$ and $0.5 \%$ $\mathrm{nC}$ was also significantly $(\mathrm{p}<0.001)$ reduced compared to water but by only $11.3 \%$ and $14.0 \%$ respectively (Fig. 1b and Table 1). All of the MFP dilutions returned an observed to expected ratio of less than one for reduction of $F$. graminearum radial growth (Table 1).

\section{Wheat FHB disease assays}

The plate sensitivity assay showed MFP could reduce the growth of $F$. graminearum in vitro, though to a lesser extent than CS. Therefore, it was necessary to evaluate if MFP could control or reduce the impact of FHB disease in planta. Wheat cv Avatar plants were treated twice, with applications one week apart, with either MFP, or the components $\mathrm{nC}, \mathrm{CS}$, or water as the control. Point inoculations were performed with $F$. graminearum or mock-inoculum on the wheat heads when they reached mid-anthesis. Inoculated heads were scored for disease spread and progression at 7 dpi, 14 dpi and 21dpi (Fig. 2a, b). FHB spread significantly increased $(\mathrm{p}<0.05)$ from $7 \mathrm{dpi}$ to $14 \mathrm{dpi}$ and from $14 \mathrm{dpi}$ to $21 \mathrm{dpi}$, irrespective of treatment. At all three time points, FHB spread was significantly lower $(\mathrm{p}<0.05)$ following MFP treatment than water treatments (Fig. 2b). At 7 dpi disease was lower than the water control by $30 \%$, at 14 dpi by $28 \%$ and at 21 dpi by $14 \%$ with MFP. The disease scores on MFP and CS were statistically similar. No reduction in disease spread was observed on $\mathrm{nC}$ treated plants (Fig. 2b). By 21 dpi, FHB infected heads on Water and $\mathrm{nC}$ treated plants were predominantly bleached and had little or no chlorophyll present. Whereas chlorophyll was still visible on the heads of plants treated with either CS or MFP at 21dpi (Fig. 2a). No FHB disease was recorded on mock-inoculated heads (Data not shown).

\section{MFP impact on grain yield}

Plants were subsequently harvested, the number of grains per head and grain weight per head were recorded, and the average grain weight calculated (Fig. 3).

\section{Average grain weight}

On healthy mock-inoculated wheat heads, the average grain weight of MFP treated plants was statistically similar to untreated, water only control plants (Fig. 3a). The average grain weight of mock-inoculated wheat heads following $\mathrm{nC}$ treatment was similar statistically to the other three treatments. However, the average grain weight per head of mock-inoculated CS treated plants was significantly lower than that of untreated, water only control plants (by 9\%, p = 0.05), and MFP (by 12\%, p = 0.007).

The $F$. graminearum infection on inoculated heads reduced the average grain weight per head by $65 \%$, $62 \%, 45 \%$, and $52 \%$ for water, nC, CS and MFP treatments respectively compared to mock-inoculated plants. However, the average grain weight was significantly higher for CS treated (by 41\%, p = 0.031) and MFP treated (by 38\%, $\mathrm{p}=0.038$ ) $F$. graminearum 
a
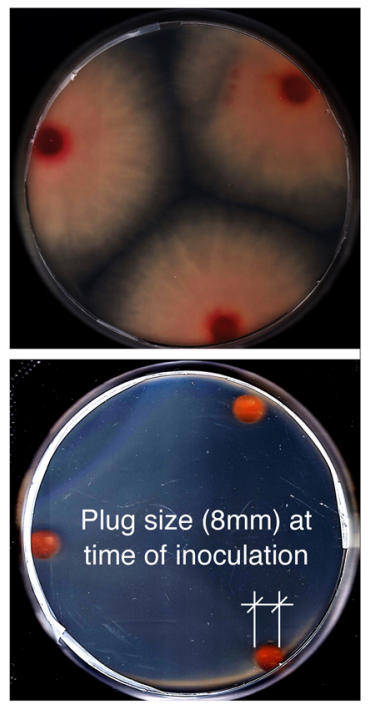

$0.34 \%$
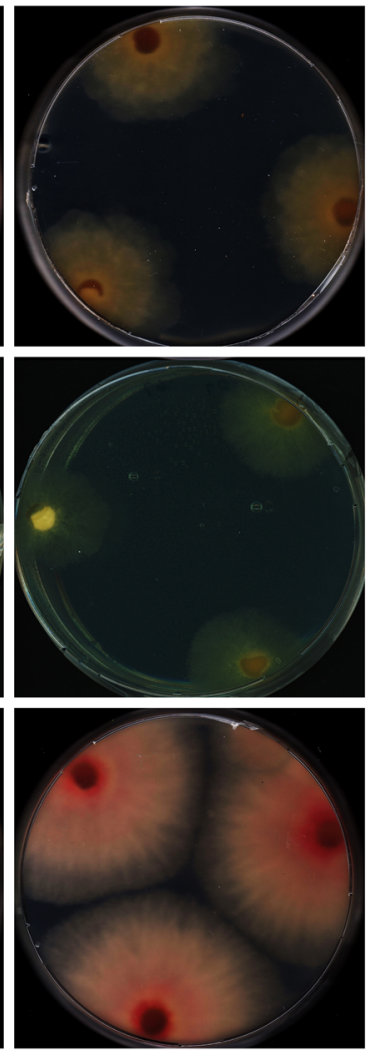

$0.5 \%$
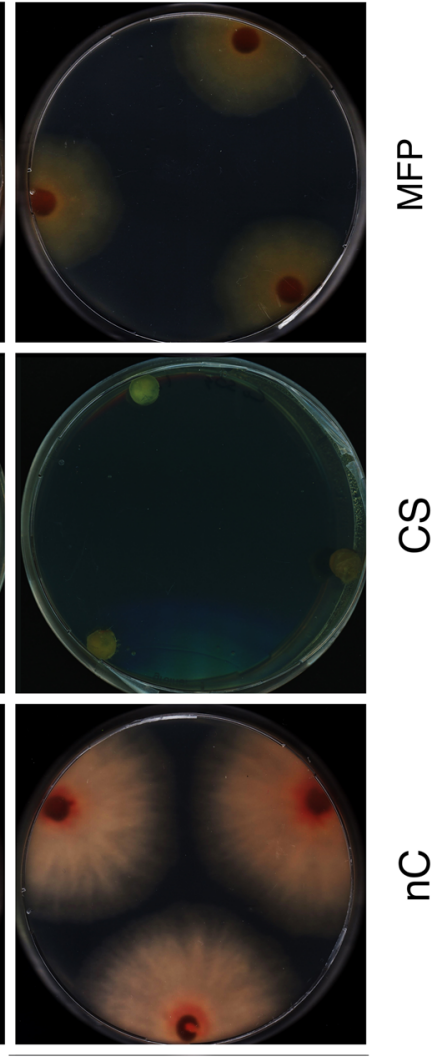

b

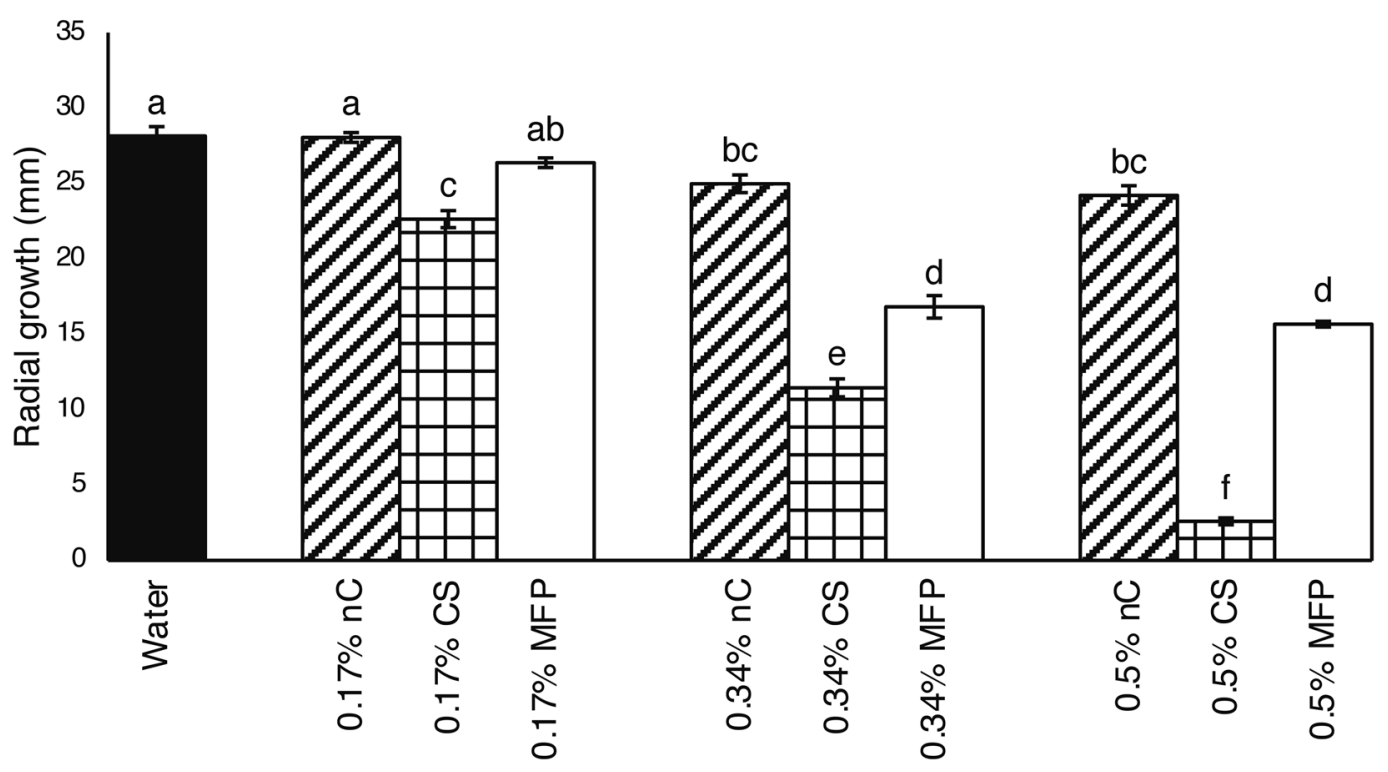

infected heads compared to the infected heads treated with water only. The average grain weight of nC treated $F$. graminearum infected heads was statistically similar to the infected water only treated heads (Fig. 3a). 
\Fig. 1 Fusarium graminearum in vitro sensitivity assays. Plates were amended with MFP, nC or CS. Three treatment concentrations were used: $0.5 \%, 0.34 \%$ and $0.17 \%$. Sterilised distilled water was used as a control. (a) Representative images of $F$. graminearum inoculated plates at 4 dpi. Plug size at time of inoculation is shown for comparison. (b) Statistical analysis of growth at $4 \mathrm{dpi}$. Results represent the mean (three plates per treatment concentration with three plugs per plate, repeated in three independent experiments, $n=27$ ) and error bars indicate \pm SEM. Different letters denote significant $(\mathrm{p} \leq 0.05)$ differences between treatments

Grain weight per head

On healthy mock-inoculated wheat heads, grain weight per head was highest following MFP treatment and significantly heavier compared to grain from mock-inoculated water only treated heads (by $32 \%$, $\mathrm{p}<0.001$ ) (Fig. 3b). For the mock-inoculated heads both $\mathrm{CS}$ and $\mathrm{nC}$ treatments were not statistically different to either MFP or water treated heads (Fig. 3b).

For $F$. graminearum infected heads, grain weight per head was lower by $67 \%, 73 \%, 62 \%$ and $63 \%$ for water, $\mathrm{nC}, \mathrm{CS}$ and MFP treated heads respectively when compared to mock-inoculated heads. The grain weight per head was statistically comparable across all treatments on $F$. graminearum infected heads (Fig. $3 b$ ).

\section{Grain number/head}

On mock-inoculated heads, the number of grains per head was significantly higher for MFP treated heads (by $29 \%, \mathrm{p}=0.01$ ) compared to mock-inoculated water only treated plants. The grain number per head following treatment with the components $\mathrm{nC}$ and CS on mock-inoculated heads were statistically comparable to those treated with water only (Fig. 3c).

On $F$. graminearum infected heads compared to healthy mock-inoculated heads, the grain number per head was significantly less for all treatments $(\mathrm{p}<$ 0.001 ), water, $\mathrm{nC}, \mathrm{CS}$ and MFP by $25 \%, 35 \%, 32 \%$ and $25 \%$ respectively. The $F$. graminearum infected heads, had a significantly higher number of grains per head recorded for MFP treated $(28 \%, \mathrm{p}=0.01)$ plants compared to those treated with water only. The grain number following treatment with the components $\mathrm{nC}$ and CS on $F$. graminearum infected heads were statistically comparable to water only controls (Fig. 3c).
Phytotoxicity of copper

CS treated plants had significantly lower average grain weight per head than water and MFP treated plants. In order to assess any phytotoxicity caused by the copper component of MFP, wheat cv Avatar were treated with MFP, CS and $\mathrm{nC}$, and seven days later, necrotic symptom coverage was evaluated by staining and ImageJ. Necrotic symptoms following $\mathrm{nC}$ treatment were not significantly different to the water treated leaves. While average necrosis coverage on MFP treated leaves was $3.4 \%$, significantly higher than $\mathrm{nC}$ and water treated leaves $(\mathrm{p} \leq 0.02)$. However, necrosis coverage on MFP treatments were statistically comparable, regardless of light intensity level; $200 \mu \mathrm{mol} \mathrm{m}{ }^{-2} \mathrm{~s}^{-1}$, high light (HL) or $45 \mu \mathrm{mol}$ $\mathrm{m}^{-2} \mathrm{~s}^{-1}$, low light (LL) (Supplementary Fig. S2 on the Online Resource 1). The average necrosis coverage on CS treated leaves was the highest, at $12.4 \%$, significantly higher than found on MFP treated leaves ( $\mathrm{p}$ $\leq 0.03)$ and all other treatments $(\mathrm{p}<0.001)$. Microscopy revealed the necrosis symptoms were due to the cell death of epidermal and mesophyll cells (Fig. 4b).

\section{Zymoseptoria tritici in vitro sensitivity assays}

To test the sensitivity of the fungal pathogen $Z$. tritici to MFP and to compare the effect of the components, the fungus was grown on agar amended with differing concentrations of MFP and components $\mathrm{nC}$ and CS. Radial growth was measured two weeks after inoculation (Fig. 5a).

On $0.17 \%$ MFP plates, Z. tritici growth was significantly lower (by 44.5\%, p < 0.001) compared to water, while growth on $\mathrm{nC}$ and $\mathrm{CS}$ was statistically comparable to water at this concentration. Z. tritici growth on plates with $0.34 \% \mathrm{nC}, \mathrm{CS}$ and MFP was significantly lower compared to water, by $35.9 \%$ (p $=0.006), 69.3 \%(\mathrm{p}<0.001)$ and $73.2 \%(\mathrm{p}<0.001)$ respectively. Complete inhibition of fungal growth was observed on MFP and CS at $0.5 \%$ while growth on $\mathrm{nC}$ was comparable to that on water (Fig. 5b and Table 1). All of the MFP dilutions returned an observed to expected ratio of 0.9 or above for reduction of Z. tritici radial growth (Table 1). 
Table 1 Percent reduction of fungal growth in vitro by MFP components $\mathrm{nC}$ and CS alone and in combination (MFP) and their $\mathrm{E}_{\mathrm{obs}} /$ $\mathrm{E}_{\text {exp }}$ ratios

\begin{tabular}{llll}
\hline Treatments & $\begin{array}{l}F . \text { graminearum radial growth reduc- } \\
\text { tion }(\%) \pm \mathrm{SD}\end{array}$ & $\mathrm{E}_{\mathrm{obs}} / \mathrm{E}_{\mathrm{exp}} 1$ & $\begin{array}{l}Z \text {. tritici radial growth reduction } \\
(\%) \pm \mathrm{SD}\end{array}$ \\
\hline $0.17 \% \mathrm{nC}$ & $0.4 \pm 6$ & & $15.3 \pm 9.6$ \\
$0.17 \% \mathrm{CS}$ & $19.6 \pm 10.4$ & 0.3 & $21.7 \pm 11.5$ \\
$0.17 \% \mathrm{MFP}$ & $6.3 \pm 5.9$ & & $44.5 \pm 15.9$ \\
$0.34 \% \mathrm{nC}$ & $11.3 \pm 10.8$ & & $35.9 \pm 11.7$ \\
$0.34 \% \mathrm{CS}$ & $59.3 \pm 11$ & 0.6 & $69.3 \pm 10.9$ \\
$0.34 \% \mathrm{MFP}$ & $40.3 \pm 13.8$ & & $73.2 \pm 5.2$ \\
$0.5 \% \mathrm{nC}$ & $14.0 \pm 11.9$ & & $28.8 \pm 15.7$ \\
$0.5 \% \mathrm{CS}$ & $90.8 \pm 4.2$ & $0.5^{1}$ & $100.0 \pm 0$ \\
$0.5 \% \mathrm{MFP}$ & $44.3 \pm 2.5$ & $100.0 \pm 0$ \\
\hline
\end{tabular}

Observed efficiency/Expected efficiency $\left(\mathrm{E}_{\mathrm{obs}} / \mathrm{E}_{\mathrm{exp}}\right)$ ratio equal to 1 indicates additivity, ratios $>1$ indicate synergy, and ratios $<1$ indicate antagonism

${ }^{1}$ Abbott's method is less reliable where a control level of a single component is $>70 \%$ (Gisi, 1996)

\section{Zymoseptoria tritici disease assays}

To test if the inhibition of $Z$. tritici growth by MFP found in the in vitro assay extended to in planta, disease assays were performed (Fig. 6). Wheat seedlings were treated twice with either water, $0.5 \%$ or $1 \%$ MFP treatments one week apart and inoculated with Z. tritici one day after the second treatment. Twentyone days post inoculation, plants were scored for disease severity and pycnidia coverage. On plants treated with either concentration of MFP, these parameters were statistically similar to the water-treated plants. Though not significantly different, pycnidia coverage on both MFP concentrations was approximately $18 \%$ lower than on water treated plants (Fig. 6).

\section{Discussion}

In this study, sensitivity assays determined that MFP could reduce the growth of $F$. graminearum, and $Z$. tritici under in vitro conditions. Previously we demonstrated that MFP negatively inhibits the germination and development of the biotrophic pathogen B. graminis $\mathrm{f}$. sp. tritici in vitro (Twamley et al., 2019). Together these results support the antifungal activity of MFP.

The Abbotts equation can be used to measure the synergism/additivity/antagonism of fungicide mixtures (Gisi, 1996) as well as natural compounds mixed with fungicides (Rahman et al., 2014). The Abbotts equation indicates a synergistic interaction of the $\mathrm{nC}$ and CS components at the $0.17 \%$ rate for $Z$. tritici control in vitro. For example, at this low concentration rate $(0.17 \%)$, neither component ( $\mathrm{nC}$ or $\mathrm{CS}$ ) on its own significantly reduced $Z$. tritici growth on plates whereas MFP did. Therefore, at low concentrations, these components mixed are in fact more effective against $Z$. tritici than as individual treatments. The $\mathrm{E}_{\mathrm{obs}} / \mathrm{E}_{\exp }$ ratio at this application rate was 1.3 which also supports this synergism. Synergism between copper and salicylaldehyde benzoylhydrazone (SBH) have also been reported, displaying greater antifungal activity against Stagonospora nodorum and the oomycete Phytophthora capsici in vitro (Young et al., 2016). Conversely, at the $0.34 \%$ rate, an antagonistic interaction of the MFP components is indicated in terms of in vitro $Z$. tritici control. The $\mathrm{nC}$ component $(0.34 \%)$ showed antifungal activity towards $Z$. tritici and significantly reduced growth on plates suggesting it contributes to the antifungal activity exhibited by MFP. Yeast and lactic acid bacteria have both been demonstrated to be antifungal against plant pathogens (Punja. \& Utkhede 2003; Gajbhiye \& Kapadnis, 2016). The results of the Abbott's equation are less reliable at the $0.5 \%$ rate as the control level of one of the components (CS) is higher than 70\% (Gisi, 1996). The effect of MFP on Z. tritici growth was statistically comparable to $\mathrm{CS}$ at all three concentrations which suggests CS is the predominant active ingredient of the MFP mix against this fungal species. There was no 
a

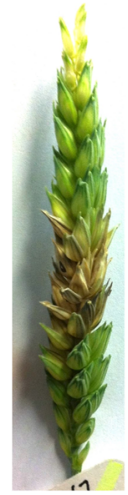

$\stackrel{\bar{\Phi}}{\stackrel{\bar{w}}{\zeta}}$
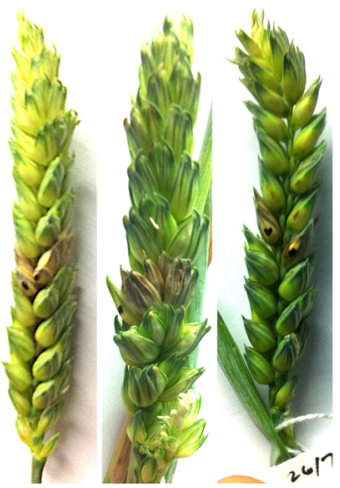

O O

$7 \mathrm{dpi}$

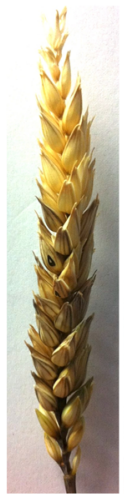

$\stackrel{\bar{\Phi}}{\stackrel{ \pm}{\pi}}$
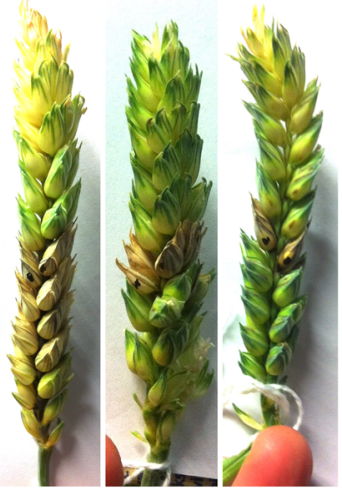

O O

$\stackrel{\text { 崖 }}{\Sigma}$

14 dpi
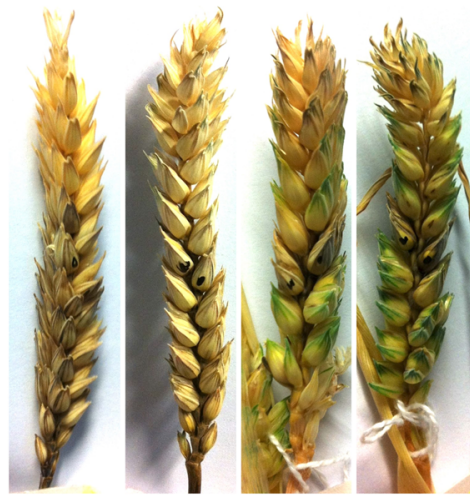

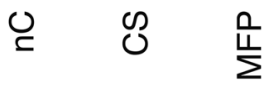

21 dpi

b

$b$
0
0
0
0
0
0
0
0
0
0
0
0
0
0
0
$\frac{0}{0}$
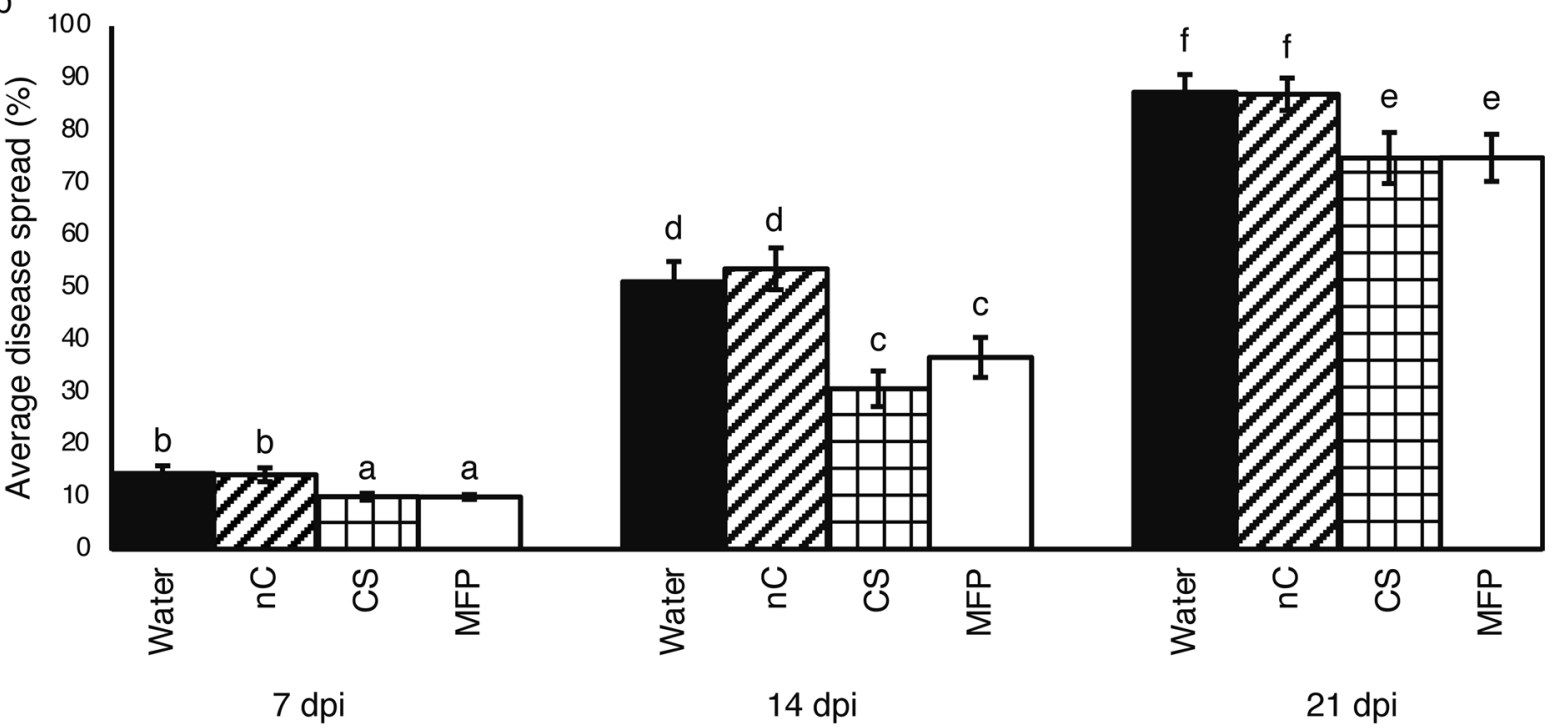

Fig. 2 FHB disease severity scores. Mature wheat cv Avatar plants were treated twice with $0.5 \%$ MFP, $0.5 \%$ CS, $0.5 \%$ $\mathrm{nC}$ or water, with treatments a week apart. Point inoculations were undertaken as wheat heads reached mid-anthesis. Heads were inoculated with $F$. graminearum. Mock inoculations were made with $0.02 \%$ Tween 20 (not shown). (a) Representative images of FHB disease spread from three independent experiments. Images show disease progression at 7, 14 and 21 dpi on

one wheat head treated with either Water, nC, CS or MFP (b) At 7, 14 and $21 \mathrm{dpi}$, percent disease coverage was recorded. Results represent the mean (12 plants per treatment with two heads per plant, repeated in three independent experiments, $\mathrm{n}=72$ ) and error bars indicate \pm SEM. Different letters denote significant $(\mathrm{p} \leq 0.05)$ differences between treatments per time point

significant reduction in STB symptoms post inoculation with $Z$. tritici in planta, though pycnidia coverage was approximately $18 \%$ lower following both concentrations of MFP treatment. As Z tritici has a latent period of up to 10 days (Fones et al. 2017; Haueisen

et al., 2018), any resistance afforded by MFP may have diminished before the onset of the pathogen's necrotrophic disease phase. For any future Z. tritici disease assays, treatment timing and inoculum level should be reconsidered. 


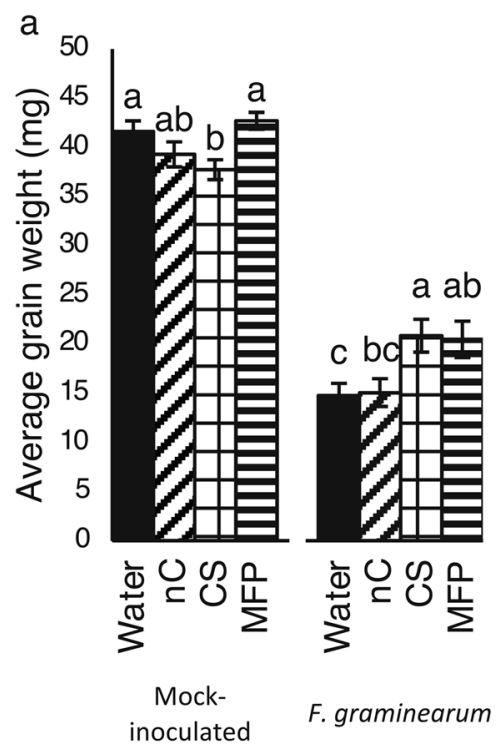

b

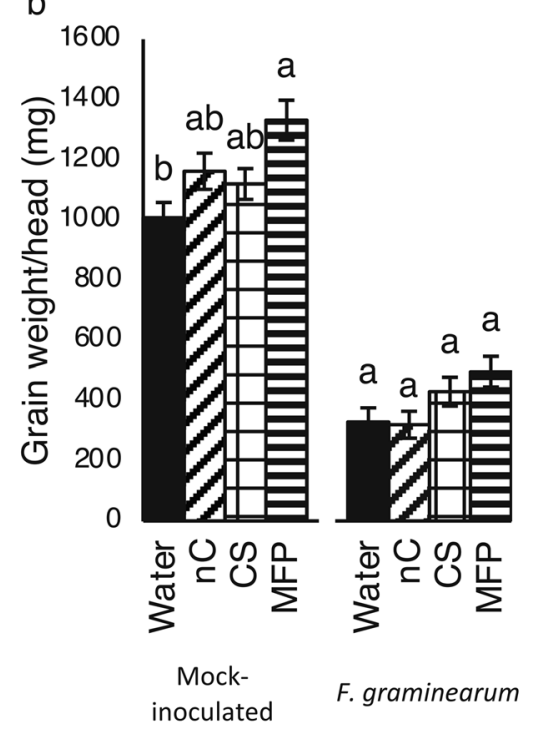

C

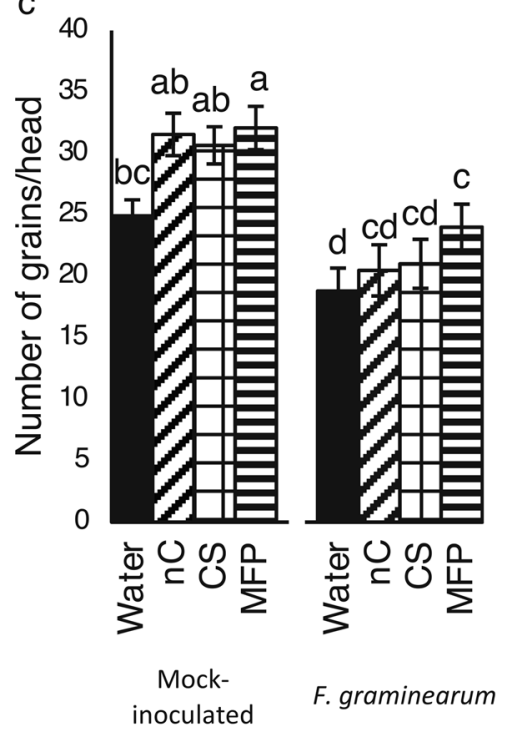

Fig. 3 Evaluation of grain development on MFP, CS and nC treated wheat plants mock-inoculated or infected with $F$. graminearum. Mature wheat cv Avatar plants were treated twice with $0.5 \% \mathrm{MFP}, 0.5 \% \mathrm{CS}, 0.5 \% \mathrm{nC}$ or Water, with treatments a week apart. At mid-anthesis, point inoculations were performed with $F$. graminearum or $0.02 \%$ Tween 20 (mock-inoculated). (a) Average grain weight, (b) Grain

The components of MFP, $\mathrm{nC}$ and CS individually (at a rate of $0.5 \%$ ), also show antifungal activity towards $F$. graminearum in vitro. However, the effectiveness of MFP against $F$. graminearum was less than $\mathrm{CS}$ alone but greater than $\mathrm{nC}$ alone. This suggests that for $F$. graminearum control, nC and CS have an antagonistic interaction when mixed as MFP in vitro, since all dilutions of the treatment returned an Abbott's equation ratio of less than 1. It does not necessarily follow, that the effect of a treatment in vitro, will be observed in planta (Palazzini et al., 2018). In fact, we did not observe this antagonism of the components, on MFP treated plants, FHB reduction was similar ( 14\%) following CS and MFP treatment whereas little control was afforded by $\mathrm{nC}$ alone. Therefore, the copper component of MFP is probably the influencing factor in the reduced FHB spread on MFP treated plants. Although, other studies have reported a reduction in FHB disease incidence by biological controls containing bacteria such as Bacillus by up to $67 \%$ (Nourouzian et al., 2006).

The evaluation of the grain development on wheat heads infected with $F$. graminearum can largely weight per head, (c) Number of grains per head. Results represent the mean (12 plants per treatment with two heads per plant, repeated in three independent experiments, $n=72$ ) and error bars indicate \pm SEM. Different letters denote significant (p $\leq 0.05$ ) differences $(\mathrm{a}, \mathrm{b})$ within mock-inoculated and $F$. graminearum infected groups, (c) across mock-inoculated and $F$. graminearum infected groups

be explained by the disease scores. However, on $F$. graminearum infected plants, MFP treated heads had a higher number of grains per head relative to the water only control (28\%). Other studies have reported a reduction in FHB disease-associated loss in grain weight by biological controls containing bacteria such as Pseudomonas, Streptomyces, and Bacillus (Khan et al., 2001; Nourouzian et al., 2006; Khan \& Doohan 2009), and yeast such as Cryptococcus strains (Khan et al., 2001). It would appear that MFP may extend protection to grain quantity, as $F$. graminearum infected MFP treated plants produced a statistically comparable number of grains per head to healthy mock-inoculated water control plants and a significantly higher number of grains compared to $F$. graminearum infected water treated plants. Interestingly, for healthy mock-inoculated heads, the number of grains per head and grain weight per head for MFP treated plants was significantly higher than for mockinoculated water only treated plants. This suggests that on healthy uninfected plants, MFP can improve yield. Similarly, some treatments with antagonistic bacterial strains in the absence of the pathogen 

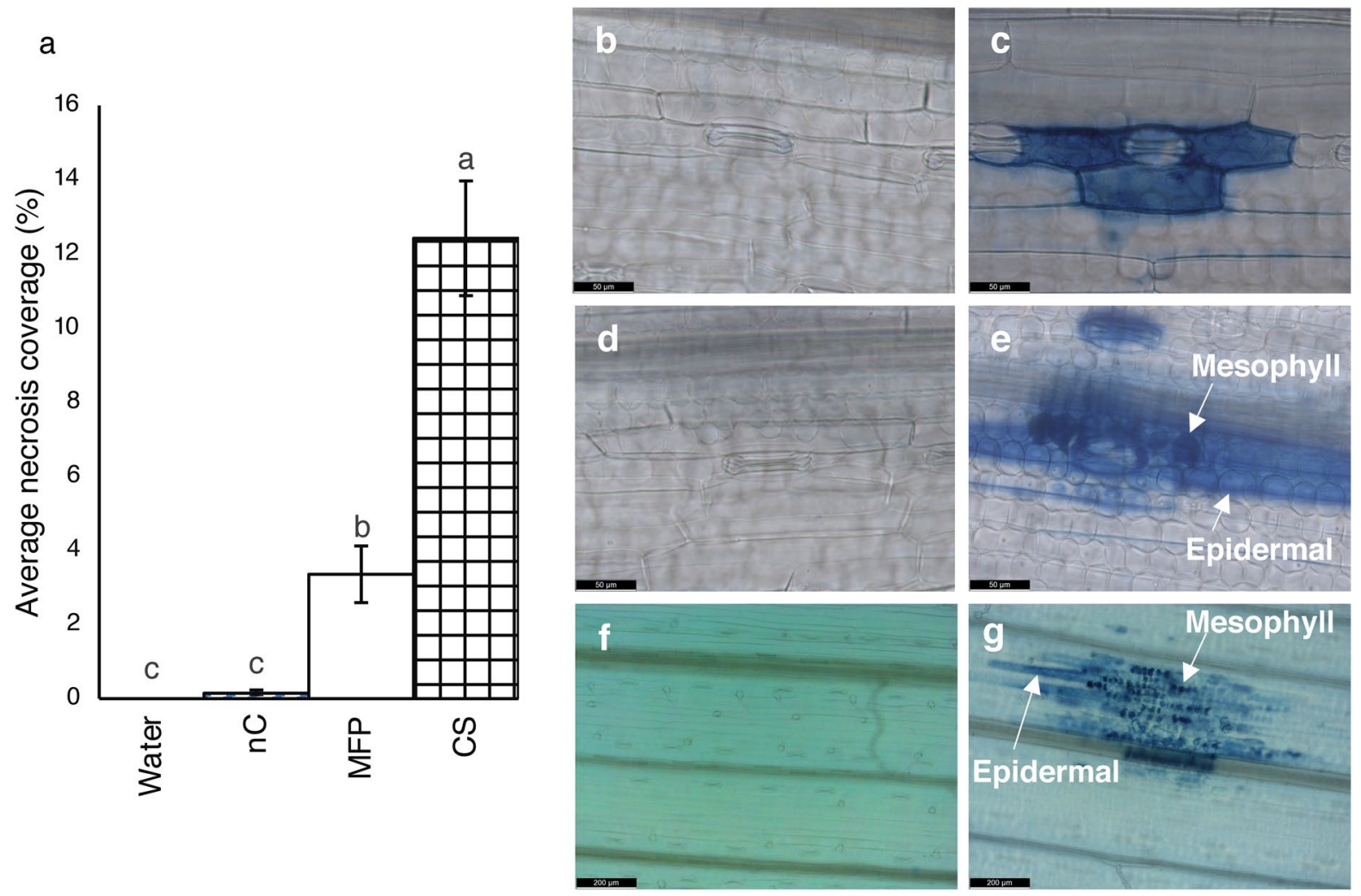

Fig. 4 Phytotoxicity of copper. Post treatment with water, $0.5 \% \mathrm{nC}, 0.5 \% \mathrm{MFP}$ or $0.5 \% \mathrm{CS}$, on wheat cv Avatar, under high light $200 \mu \mathrm{mol} \mathrm{m} \mathrm{m}^{-2} \mathrm{~s}^{-1}$ light intensity. Coverage of symptoms on four representative leaf sections per leaf for three leaves (one leaf per plant of three plants) $(n=36)$ were measured. Two independent experiments were performed. (a) Bars represent mean and error bars represent SEM. Letters denote significant differences ( $\mathrm{p} \leq 0.05)$ between treatments. ( $b, \mathrm{~d}$ and f) water treated tissue and (c, e, and g) MFP treated tissue (c) epidermal cell death (e) mesophyll and epidermal cell death (g) necrotic spot with mesophyll and epidermal cell death. Scale bars for b, c, d and e represent $50 \mu \mathrm{m}$, and $\mathrm{f}$, g, represents $200 \mu \mathrm{m}$ increase yield in wheat (Nourouzian et al., 2006). This was not found for plants treated with the components $\mathrm{nC}$ and $\mathrm{CS}$. In fact, when the average grain weight was calculated, CS treated mock-inoculated plants had a significantly lower average grain weight than mock-inoculated MFP and water only treated plants. Several studies have reported such copper inhibition of growth and that copper causes oxidative damage in crops including wheat and maize (Adrees et al., 2015). These results suggest a beneficial effect to grain development by MFP, increasing both grain weight per head and number of grains per head. Therefore, MFP may provide FHB control without inducing oxidative damage, protecting yields in the presence of $F$. graminearum and also promoting yields in the absence of the pathogen. Microbial fermentation products enhance nutrient uptake and transport in sunflower (Helianthus annuus L.) (Tian et al., 2015) as well as significantly increasing plant growth and nutrient uptake in almond (Prunus dulcis [Mill.] D. A. Webb) (Saa et al., 2015). On winter wheat, a foliar applied amino acid based biostimulant increased yield by up to $11 \%$ (Popko et al., 2018) while an amino acid and yeast extract improved wheat productivity and grain quality by significantly increasing carbohydrates, protein and decreasing fibre (Hammad \& Ali, 2014). Further testing is required to investigate the underlying mechanism by which MFP promotes grain development. 
a

Water
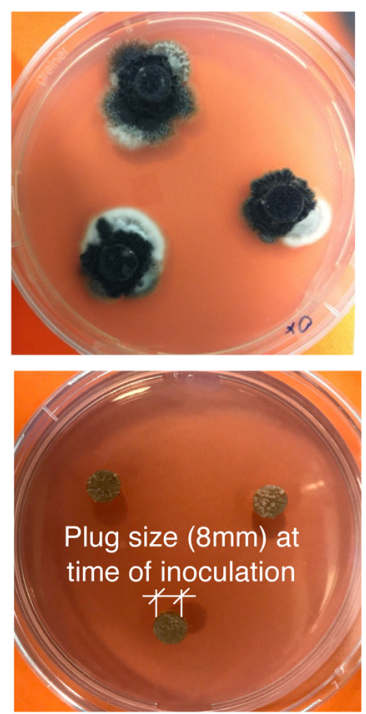

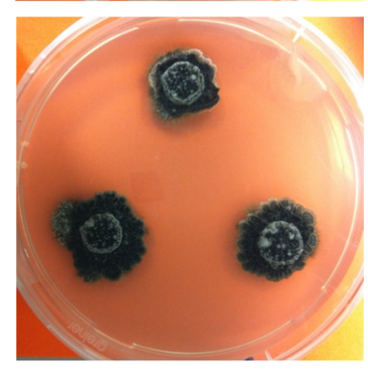

$0.17 \%$
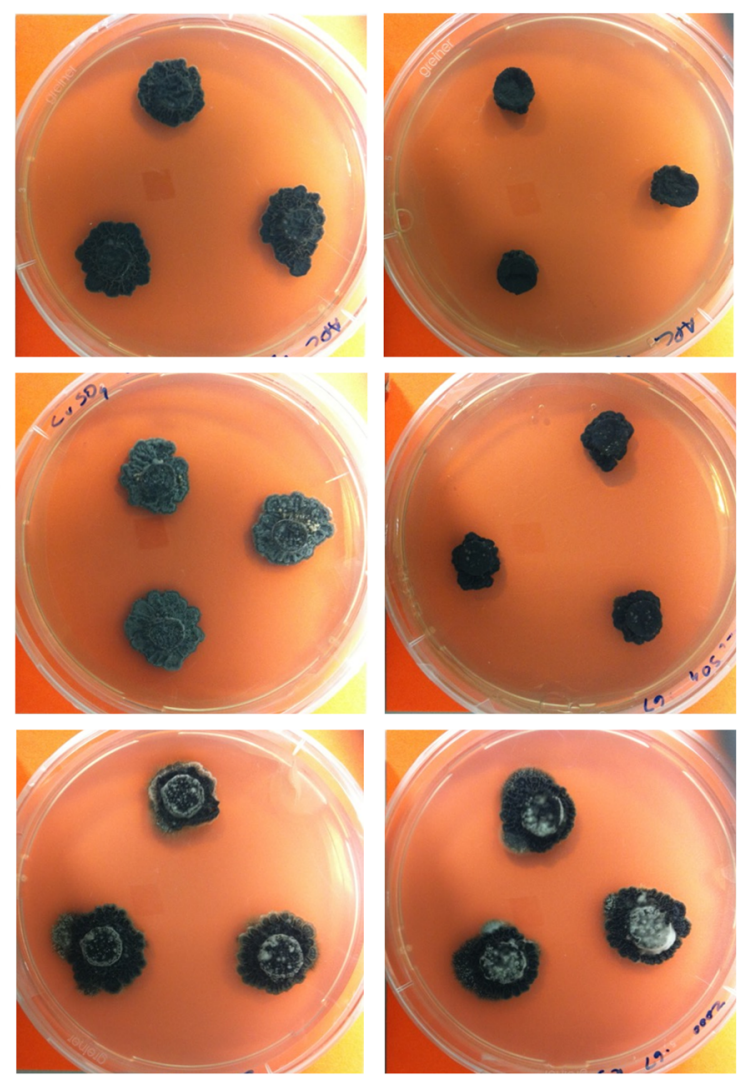

$0.5 \%$

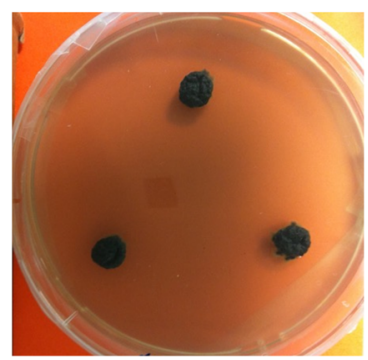

品

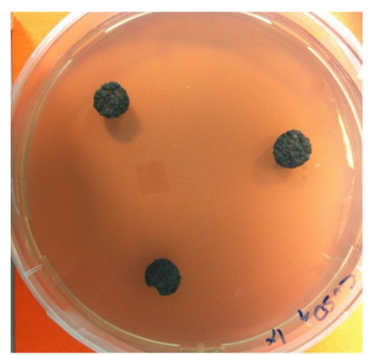

$\mathcal{U}$

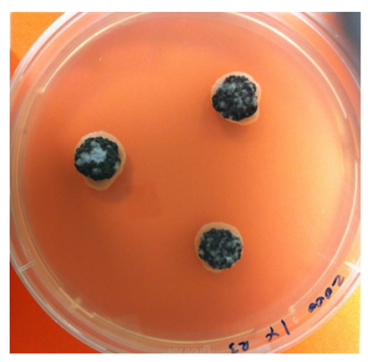

b

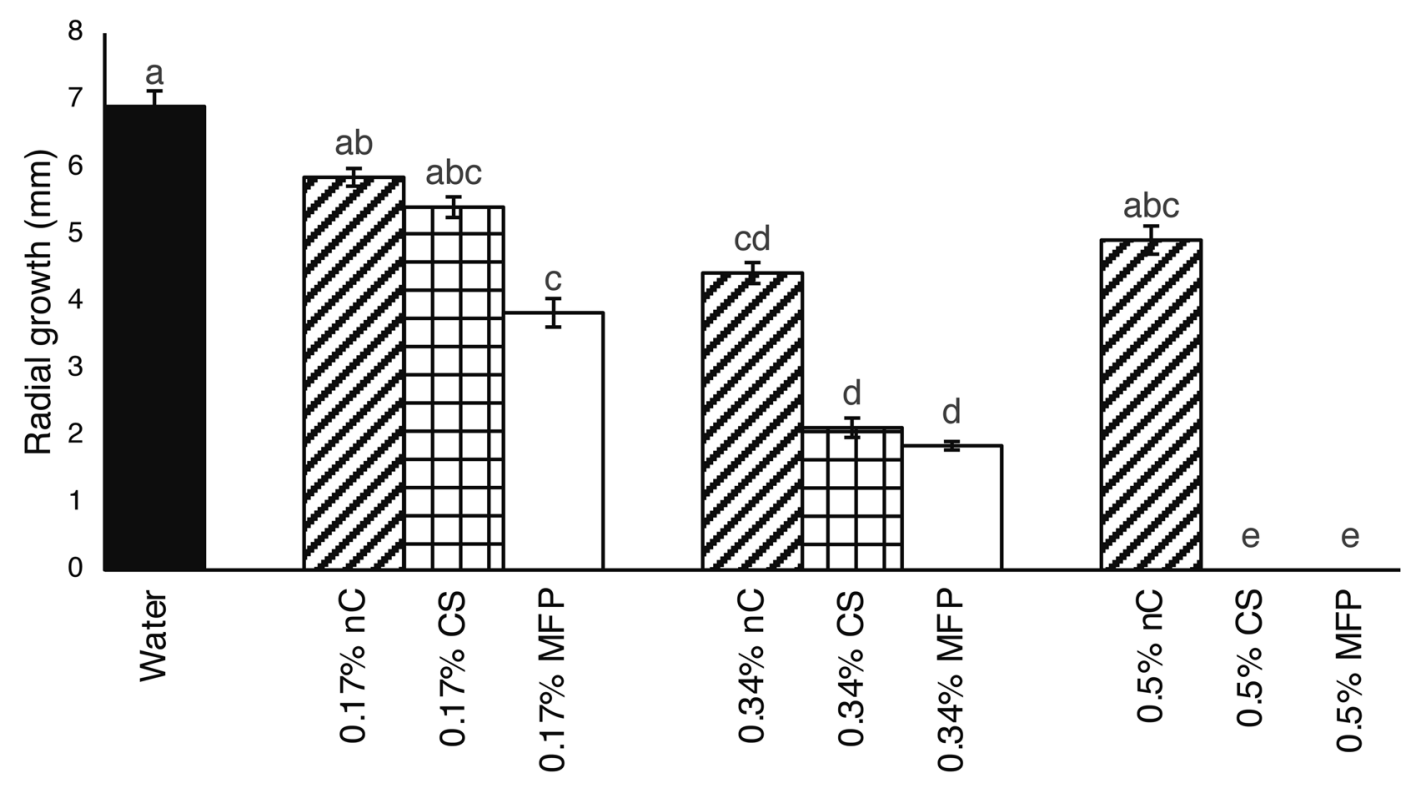


4Fig. 5 Assessment of the sensitivity of Z. tritici to MFP, nC and CS. Plates were amended with MFP, nC or CS. Three treatment concentrations were assessed: $0.5 \%, 0.34 \%$ and $0.17 \%$. Sterilised distilled water was used as a control. Fourteen days post inoculation (dpi), radial growth was measured from the circumference of the original $8 \mathrm{~mm}$ plug. (a) Representative images of $Z$. tritici growth on amended agar from three independent experiments. Image of plug size at time of inoculation is included. (b) Results represent the mean (three plates per treatment concentration with three plugs per plate, repeated in three independent experiments, $n=27)$ and error bars indicate \pm SEM. Different letters denote significant ( $\mathrm{p} \leq$ $0.05)$ differences between treatments
The copper content of MFP is low, $0.02 \%$ of the recommended application rate, compared to typically used fungicide rates of $\geq 0.2 \%$ (Arya \& Perelló, 2010). This reduced copper dose may facilitate greater copper penetration through the cell membrane and uptake into pathogen cells by forming peptide and amino acid complexes. It has been proposed this may also increase toxicity to plant cells, but we did not observe this effect with MFP compared to CS under different light intensities (Pertot et al., 2006; Malachová, Praus, Rybková \& Kozák, 2011). The application of highly soluble copper formations such
Fig. 6 Z. tritici disease spread and pycnidia coverage. Wheat cv Avatar seedlings were treated twice with water, $0.5 \%$ or $1 \%$ MFP, with treatments one week apart. One day after the second treatment, plants were inoculated with Z. tritici. At $21 \mathrm{dpi}$, disease spread and pycnidia coverage was measured (Eyal et al., 1987). Results represent the mean (three leaves/plant of ten plants per treatment, repeated in two independent experiments, $n=60$ ) and error bars indicate \pm SEM. Different letters denote significant ( $\mathrm{p}$ $\leq 0.05$ ) differences between treatments

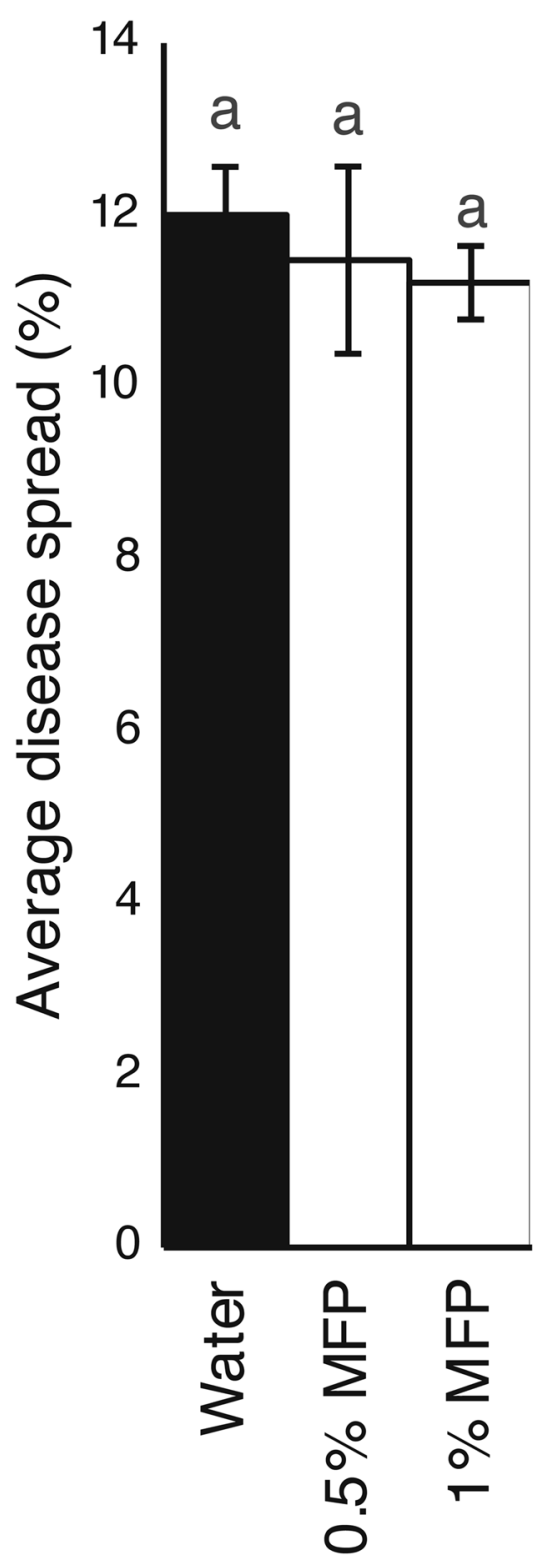


as copper sulphate or copper nitrate in addition to high and frequent application rates can lead to copper phytotoxicity. Typical symptoms of copper phytotoxicity on leaves consist of chlorosis, darkening of axial and abaxial surfaces, necrotic spots, and leaf margin burn (Lamichhane et al., 2018). This is in line with the areas of cell death that we observed with CS and MFP although, the areas of cell death were significantly higher after CS application than $\mathrm{nC}$ or MFP. Copper toxicity may be enhanced by high light intensities due to photoinhibition and the production of hydroxyl radicals (Yruela et al., 1996) but this was not observed with MFP as lesion coverage was similar under both high and low light conditions tested. Therefore, MFP does not lead to the same phytotoxicity as the same concentration of CS.

As this study used a single batch of MFP and $\mathrm{nC}$, it is possible that the effects found may only be attributed to that batch. However, the product was manufactured by a commercial company to standard and therefore batch effects would be expected to be minimal. Further assessments could be performed across batches to ensure a consistent effect.

In conclusion, MFP had a direct antifungal effect against the non-biotrophic pathogens $F$. graminearum and $Z$. tritici in vitro and both of the components of MFP, $\mathrm{nC}$ and CS, play a role in that activity. However, the contribution of each component to the effect may vary depending on the fungal species. For example, an antagonistic interaction was observed for the MFP components against $F$. graminearum in vitro but not in planta where MFP may protect against the phytotoxic impacts of the copper component. While antagonism or synergism of the components was concentration dependent against $Z$. tritici.

The results suggest that MFP provides some protection against FHB in planta and in the absence of the disease MFP significantly enhanced grain development and yield. Field trials will be required to confirm the feasibility of MFP use in the production of wheat.

Acknowledgements The Scholarship of TT was supported by Alltech Crop Science. The authors thank Gordon Kavanagh for excellent technical help. Aisling Reilly, Stevie Kehoe, Sujit Jung Karki, Anna Tiley, Enrique Alcalde, Thalia Christodoulou, Amal Kahla, Myriam Deshaies, Marquisha Paul, Richard Lally and Michael Byrne for advice.
Author Contributions TT, MG and AF designed the experiments. TT performed the experiments. AF supervised the project. TT wrote the manuscript, AF and MG revised the manuscript.

Funding Open Access funding provided by the IReL Consortium.

\section{Declarations}

Conflict of interest statement The research was funded by Alltech Crop Science (Ireland) who also provided the MFP. MG was employed by the company Alltech.

The authors declare that the research was conducted in the absence of any commercial or financial relationships that could be construed as a potential conflict of interest. Collection of data, analysis, and interpretation was carried out independently of Alltech. The authors have the full data set available.

Research involving human participants and/or animals This research did not involve human participants or animals.

Consent for publication All authors consent to this submission.

Open Access This article is licensed under a Creative Commons Attribution 4.0 International License, which permits use, sharing, adaptation, distribution and reproduction in any medium or format, as long as you give appropriate credit to the original author(s) and the source, provide a link to the Creative Commons licence, and indicate if changes were made. The images or other third party material in this article are included in the article's Creative Commons licence, unless indicated otherwise in a credit line to the material. If material is not included in the article's Creative Commons licence and your intended use is not permitted by statutory regulation or exceeds the permitted use, you will need to obtain permission directly from the copyright holder. To view a copy of this licence, visit http://creativecommons.org/licenses/by/4.0/.

\section{References}

Adrees, M., Ali, S., Rizwan, M., Ibrahim, M., Abbas, F., Farid, M., Zia-Ur-Rehman, M., Irshad, M. K., \& Bharwana, S. A. (2015). The effect of excess copper on growth and physiology of important food crops: a review. Environmental Science And Pollution Research, 22(11), 81488162. https://doi.org/10.1007/s11356-015-4496-5

Arya, A., \& Perelló, A. (2010). Management of fungal plant pathogens. CAB International. https://doi.org/10.1079/ 9781845936037.0000

Chalfoun, N. R., Durman, S. B., Budeguer, F., Caro, M., Bertani, R. P., Di Peto, P., Stenglein, S. A., Filippone, M. P., Moretti, E. R., Díaz Ricci, J. C., Welin, B., \& Castagnaro, A. P. (2018a). Development of PSP1, a Biostimulant Based on the Elicitor AsES for Disease Management in Monocot and Dicot Crops. Frontiers in plant science, 9, 844. https://doi.org/10.3389/fpls.2018.00844 
Chalfoun, N., Durman, S., González-Montaner, J., Reznikov, S., De Lisi, V., González, V., Moretti, E. R., Devani, M. R., Ploper, L. D., Castagnaro, A. P., \& Welin, B. (2018b). Elicitor-Based Biostimulant PSP1 Protects Soybean Against Late Season Diseases in Field Trials. Frontiers In Plant Science, 9. https://doi.org/10.3389/fpls.2018.00763

Cahalan, C., \& Law, C. N. (1979). The genetical control of cold resistance and vernalisation requirement in wheat. Heredity, 42(2), 125-132.

DAFM (2019) Winter Cereal Recommended Lists 2019. Accessed August 9, 2019 from https://www.agriculture. gov.ie

Directive 2009/128 of the European Parliament and of the Council of 21 October 2009 establishing a framework for Community action to achieve the sustainable use of pesticides.

Eyal, Z., Scharen, A. L., Prescott, J. M., \& van Ginkel M. (1987). The Septoria Diseases of Wheat: Concepts and Methods of Disease Management. Mexico, D.F.: CIMMYT.

Figueroa, M., Hammond-Kosack, K., \& Solomon, P. (2017). A review of wheat diseases-a field perspective. Molecular Plant Pathology, 19(6), 1523-1536. https://doi.org/10. 1111/mpp.12618

Fones, H., Eyles, C., Kay, W., Cowper, J., \& Gurr, S. (2017). A role for random, humidity-dependent epiphytic growth prior to invasion of wheat by Zymoseptoria tritici. Fungal Genetics And Biology, 106, 51-60. https://doi.org/10. 1016/j.fgb.2017.07.002

Forrer, H., Musa, T., Schwab, F., Jenny, E., Bucheli, T., Wettstein, F., \& Vogelgsang, S. (2014). Fusarium Head Blight Control and Prevention of Mycotoxin Contamination in Wheat with Botanicals and Tannic Acid. Toxins, 6(3), 830-849. https://doi.org/10.3390/toxins6030830

Franco, T. S., Garcia, S., Hirooka, E. Y., Ono, Y. S., \& Dos Santos, J. S. (2011). Lactic acid bacteria in the inhibition of Fusarium graminearum and deoxynivalenol detoxification. Journal of Applied Microbiology, 111(3), 739-748. https://doi.org/10.1111/j.1365-2672.2011.05074.x

Gajbhiye, M., \& Kapadnis, B. (2016). Antifungal-activity-producing lactic acid bacteria as biocontrol agents in plants. Biocontrol Science And Technology, 26(11), 1451-1470. https://doi.org/10.1080/09583157.2016.1213793

Gisi, U. (1996). Synergistic interaction of fungicides in mixtures. Phytopathology, 86(11), 1273-1279.

Hammad, S., \& Ali, O. (2014). Physiological and biochemical studies on drought tolerance of wheat plants by application of amino acids and yeast extract. Annals Of Agricultural Sciences, 59(1), 133-145. https://doi.org/10.1016/j. aoas.2014.06.018

Haueisen, J., Möller, M., Eschenbrenner, C., Grandaubert, J., Seybold, H., Adamiak, H., \& Stukenbrock, E. (2018). Highly flexible infection programs in a specialized wheat pathogen. Ecology And Evolution, 9(1), 275-294. https:// doi.org/10.1002/ece3.4724

Jochum, C., Osborne, L., \& Yuen, G. (2006). Fusarium head blight biological control with Lysobacter enzymogenes strain C3. Biological Control, 39(3), 336-344. https://doi. org/10.1016/j.biocontrol.2006.05.004

Kema, G., \& van Silfhout, C. (1997). Genetic Variation for Virulence and Resistance in the Wheat-Mycosphaerella graminicola Pathosystem III. Comparative Seedling and Adult Plant Experiments. Phytopathology®, 87(3), 266272. https://doi.org/10.1094/phyto.1997.87.3.266

Kettles, G., \& Kanyuka, K. (2016). Dissecting the Molecular Interactions between Wheat and the Fungal Pathogen Zymoseptoria tritici. Frontiers In Plant Science, 7. https:// doi.org/10.3389/fpls.2016.00508

Khan, N., Schisler, D., Boehm, M., Slininger, P., \& Bothast, R. (2001). Selection and Evaluation of Microorganisms for Biocontrol of Fusarium Head Blight of Wheat Incited by Gibberella zeae. Plant Disease, 85(12), 1253-1258. https://doi.org/10.1094/pdis.2001.85.12.1253

Khan, M., \& Doohan, F. (2009). Bacterium-mediated control of Fusarium head blight disease of wheat and barley and associated mycotoxin contamination of grain. Biological Control, 48(1), 42-47. https://doi.org/10.1016/j.bioco ntrol.2008.08.015

Kheiri, A., Moosawi Jorf, S., Malihipour, A., Saremi, H., \& Nikkhah, M. (2016). Application of chitosan and chitosan nanoparticles for the control of Fusarium head blight of wheat (Fusarium graminearum ) in vitro and greenhouse. International Journal Of Biological Macromolecules, 93, 1261-1272. https://doi.org/10.1016/j.ijbiomac.2016.09. 072

Koch, E., \& Slusarenko, A. (1990). Arabidopsis Is Susceptible to Infection by a Downy Mildew Fungus. The Plant Cell, 2(5), 437. https://doi.org/10.2307/3869093

Kocourková, Z., Bradová, J., Kohutová, Z., Slámová, L., Vejl, P., \& Horčička, P. (2008). Wheat breeding for the improved bread-making quality using PCR based markers of glutenins. Czech Journal Of Genetics And Plant Breeding, 44(No. 3), 105-113. https://doi.org/10.17221/ 20/2008-cjgpb

Kristoffersen, R., Jørgensen, L., Eriksen, L., Nielsen, G., \& Kiær, L. (2020). Control of Septoria tritici blotch by winter wheat cultivar mixtures: Meta-analysis of 19 years of cultivar trials. Field Crops Research, 249, 107696. https:// doi.org/10.1016/j.fcr.2019.107696

Lamichhane, J., Osdaghi, E., Behlau, F., Köhl, J., Jones, J., \& Aubertot, J. (2018). Thirteen decades of antimicrobial copper compounds applied in agriculture. A review. Agronomy For. Sustainable Development, 38(3). https:// doi.org/10.1007/s13593-018-0503-9

Le Mire, G., Siah, A., Brisset, M., Gaucher, M., Deleu, M., \& Jijakli, M. (2018). Surfactin Protects Wheat against Zymoseptoria tritici and Activates Both Salicylic Acidand Jasmonic Acid-Dependent Defense Responses. Agriculture, 8(1), 11. https://doi.org/10.3390/agriculture8010 011

Le Mire, G., Siah, A., Marolleau, B., Gaucher, M., Maumené, C., Brostaux, Y., Massart, S., Brisset, M. N., \& Jijakli, M. H. (2019). Evaluation of $\lambda$-Carrageenan, CpG-ODN, Glycine Betaine, Spirulina platensis, and Ergosterol as Elicitors for Control of Zymoseptoria tritici in Wheat. Phytopathology®, 109(3), 409-417. https://doi.org/10.1094/ phyto-11-17-0367-r

Lynch, K., Zannini, E., Guo, J., Axel, C., Arendt, E., Kildea, S., \& Coffey, A. (2016). Control of Zymoseptoria tritici cause of septoria tritici blotch of wheat using antifungal Lactobacillus strains. Journal Of Applied Microbiology, 121(2), 485-494. https://doi.org/10.1111/jam.13171 
Makandar, R., Nalam, V., Lee, H., Trick, H., Dong, Y., \& Shah, J. (2012). Salicylic Acid Regulates Basal Resistance to Fusarium Head Blight in Wheat. Molecular PlantMicrobe Interactions ${ }^{\circledR}, 25(3), 431-439$. https://doi.org/ 10.1094/mpmi-09-11-0232

Malachová, K., Praus, P., Rybková, Z., \& Kozák, O. (2011). Antibacterial and antifungal activities of silver, copper and zinc montmorillonites. Applied Clay Science, 53(4), 642-645. https://doi.org/10.1016/j.clay.2011.05.016

Malbrán, I., Mourelos, C., Pardi, M., Oufensou, S., Balmas, V., Delogu, G., Migheli, Q., Lori, G. A., Juárez, M. P., \& Girotti, J. R. (2020). Commercially available natural inhibitors of trichothecene production in Fusarium graminearum: A strategy to manage Fusarium head blight of wheat. Crop Protection, 138, 105313. https://doi.org/ 10.1016/j.cropro.2020.105313

McDonald, M., Renkin, M., Spackman, M., Orchard, B., Croll, D., Solomon, P., \& Milgate, A. (2019). Rapid Parallel Evolution of Azole Fungicide Resistance in Australian Populations of the Wheat Pathogen Zymoseptoria tritici. Applied and Environmental Microbiology, 85(4). https:// doi.org/10.1128/aem.01908-18

Meile, L., Croll, D., Brunner, P., Plissonneau, C., Hartmann, F., McDonald, B., \& Sánchez-Vallet, A. (2018). A fungal avirulence factor encoded in a highly plastic genomic region triggers partial resistance to septoria tritici blotch. New Phytologist, 219(3), 1048-1061. https://doi.org/10. 1111/nph. 15180

Nourozian, J., Etebarian, H. R., \& Khodakaramian, G. (2006). Biological control of Fusarium graminearum on wheat by antagonistic bacteria. Journal of Science and Technology, $28,29-38$.

Palazzini, J., Roncallo, P., Cantoro, R., Chiotta, M., Yerkovich, N., Palacios, S., Echenique, V., Torres, A., Ramírez, M., Karlovsky, P., \& Chulze, S. (2018). Biocontrol of Fusarium graminearum sensu stricto, Reduction of Deoxynivalenol Accumulation and Phytohormone Induction by Two Selected Antagonists. Toxins, 10(2), 88. https://doi.org/10. 3390/toxins 10020088

Pertot, I., Bilali, H., Simeone, V., Vecchione, A., \& Zulini, L. (2006). Efficacy evaluation and phytotoxicity assessment of copper peptidate on seven grapevine varieties and identification of the potential factors that induced copper damages on leaves. Integrated Protection in Viticulture IOBC/ wprs Bulletin, 29(11), 61-65.

Popko, M., Michalak, I., Wilk, R., Gramza, M., Chojnacka, K., \& Górecki, H. (2018). Effect of the New Plant Growth Biostimulants Based on Amino Acids on Yield and Grain Quality of Winter Wheat. Molecules, 23(2), 470. https:// doi.org/10.3390/molecules23020470

Punja, Z., \& Utkhede, R. (2003). Using fungi and yeasts to manage vegetable crop diseases. Trends In Biotechnology, 21(9), 400-407. https://doi.org/10.1016/s0167-7799(03) 00193-8

Rahman, M., Shovan, L., Hjeljord, L., Aam, B., Eijsink, V., Sørlie, M., \& Tronsmo, A. (2014). Inhibition of Fungal Plant Pathogens by Synergistic Action of Chito-Oligosaccharides and Commercially Available Fungicides. Plos ONE, 9(4), e93192. https://doi.org/10.1371/journal.pone. 0093192
R Core Team, 2016. R: A Language and Environment for Statistical Computing, Vienna, Austria. Available at: https:// www.R-project.org/.

Rojas, E., Jensen, B., Jørgensen, H., Latz, M., Esteban, P., Ding, Y., \& Collinge, D. (2020). Selection of fungal endophytes with biocontrol potential against Fusarium head blight in wheat. Biological Control, 144, 104222. https://doi.org/10.1016/j.biocontrol.2020.104222

Saa, S., Olivos-Del Rio, A., Castro, S., \& Brown, P. (2015). Foliar application of microbial and plant based biostimulants increases growth and potassium uptake in almond (Prunus dulcis [Mill.] D. A. Webb). Frontiers In Plant Science, 6. https://doi.org/10.3389/fpls.2015.00087

Scala, V., Pietricola, C., Farina, V., Beccaccioli, M., Zjalic, S., Quaranta, F., Fornara, M., Zaccaria, M., Momeni, B., Reverberi, M., \& Iori, A. (2020). Tramesan Elicits Durum Wheat Defense against the Septoria Disease Complex. Biomolecules, 10(4), 608. https://doi.org/10.3390/biom1 0040608

Schisler, D., Khan, N., Boehm, M., \& Slininger, P. (2002). Greenhouse and Field Evaluation of Biological Control of Fusarium Head Blight on Durum Wheat. Plant Disease, 86(12), 1350-1356. https://doi.org/10.1094/pdis.2002.86. 12.1350

Schneider, C., Rasband, W., \& Eliceiri, K. (2012). NIH Image to ImageJ: 25 years of image analysis. Nature Methods, 9(7), 671-675. https://doi.org/10.1038/nmeth.2089

Shin, S., Kim, K., Kang, C., Cho, K., Park, C., Okagaki, R., \& Park, J. (2014). A Simple Method for the Assessment of Fusarium Head Blight Resistance in Korean Wheat Seedlings Inoculated with Fusarium graminearum. The Plant Pathology Journal, 30(1), 25-32. https://doi.org/10.5423/ ppj.oa.06.2013.0059

Thapa, G., Gunupuru, L., Hehir, J., Kahla, A., Mullins, E., \& Doohan, F. (2018). A Pathogen-Responsive Leucine Rich Receptor Like Kinase Contributes to Fusarium Resistance in Cereals. Frontiers In Plant Science, 9. https://doi.org/ 10.3389/fpls.2018.00867

Tian, S., Lu, L., Xie, R., Zhang, M., Jernstedt, J., Hou, D., Ramsier, C., \& Brown, P. H. (2015). Supplemental macronutrients and microbial fermentation products improve the uptake and transport of foliar applied zinc in sunflower (Helianthus annuus L.) plants. Studies utilizing micro X-ray florescence. Frontiers In Plant Science, 5. https:// doi.org/10.3389/fpls.2014.00808

Twamley, T., Gaffney, M., \& Feechan, A. (2019). A Microbial Fermentation Mixture Primes for Resistance Against Powdery Mildew in Wheat. Frontiers In Plant Science, 10. https://doi.org/10.3389/fpls.2019.01241

Xue, A., Chen, Y., Voldeng, H., Savard, M., \& Tian, X. (2009). Biological control of fusarium head blight of wheat with Clonostachys rosea strain ACM941. Canadian Journal of Plant Pathology, 31, 169-179. https://doi.org/10.1556/ crc.36.2008.suppl.b.62

Yi, X., Cheng, J., Jiang, Z., Hu, W., Bie, T., Gao, D., Li, D., Wu, R., Li, Y., Chen, S., Cheng, X., Liu, J., Zhang, Y., \& Cheng, S. (2018). Genetic Analysis of Fusarium Head Blight Resistance in CIMMYT Bread Wheat Line C615 Using Traditional and Conditional QTL Mapping. Frontiers In Plant Science, 9. https://doi.org/10.3389/fpls. 2018.00573 
Young, D., Avila-Adame, C., Webster, J., Olson, B., \& Ouimette, D. (2016). Enhancing the Efficacy of Copper Fungicides through Synergism with Salicylaldehyde Benzoylhydrazones. Deutsche Phytomedizinische Gesellschaf.

Yruela, I., Pueyo, J. J., Alonso, P. J., \& Picorel, R. (1996). Photoinhibition of photosystem II from higher plants: effect of copper inhibition. Journal of Biological Chemistry,
271(44), 27408-27415. https://doi.org/10.1074/jbc.271. 44.27408

Zadoks, J., Chang, T., \& Konzak, C. (1974). A decimal code for the growth stages of cereals. Weed Research, 14(6), 415-421. https://doi.org/10.1111/j.1365-3180.1974.tb010 84.x 